\title{
Kajian Perubahan Nilai Konduktivitas Termal pada Bata Ringan dengan Penggunaan Crude Palm Oil (CPO) sebagai Bahan Penyimpan Kalor
}

\author{
Lia Laila ${ }^{1}$, Asep Yunta Darma ${ }^{1}$ \\ Teknologi Pengolahan Sawit, Fakultas Vokasi, Institut Teknologi Sains Bandung, Bekasi, Indonesia \\ E-mail: lia.laila131@gmail.com \\ yuntadarma@gmail.com
}

Informasi naskah:

Diterima

1 Juli 2020

Direvisi

15 Agustus 2020

Disetujui terbit

20 Agustus 2020

Diterbitkan

31 Agustus 2020

\begin{abstract}
Indonesia is the largest producer of Crude Palm Oil (CPO) in the world. The use of CPO is mostly for edible oils and biofuels. Even though $\mathrm{CPO}$ potential is huge, the development of $\mathrm{CPO}$ in other forms is still limited. $\mathrm{CPO}$ has a melting point of $25^{\circ} \mathrm{C}-50^{\circ} \mathrm{C}$ which is suitable to be develoved in the environment of Indonesia. This characteristic allows $\mathrm{CPO}$ to be used as phase change material. This study examines the use of $\mathrm{CPO}$ as a material to reduce the thermal conductivity of light bricks. The idea is to make the brick as a building material has the ability to maintain room conditions from fluctuative ambient temperatures. The results showed that the addition of effective CPO to reduce the thermal conductivity of light bricks was 2.5 to $7.5 \mathrm{ml}$ per $160 \mathrm{~cm}^{3}$.
\end{abstract}

Keywords: CPO, thermal conductivity, phase change material

\section{PENDAhUluAN}

Indonesia adalah negara penghasil Minyak Sawit/Crude Palm Oil (CPO) terbesar di dunia. Produk CPO merupakan bahan baku yang kemudian diolah untuk memenuhi kebutuhan pangan, energi (biofuel), kosmetik, dan lain-lain. Peran CPO dalam memenuhi energi perlu diperluas bukan saja sebagai bahan baku biofuel, tetapi juga dalam menciptakan efisiensi energi melalui pengembangan teknologi. Karakteristik CPO yang memiliki titik leleh $25^{\circ} \mathrm{C}-50^{\circ} \mathrm{C}{ }^{1)}$ memungkinkan $\mathrm{CPO}$ dapat dimanfaatkan sebagai bahan penyimpan kalor laten, yakni kalor yang dapat merubah wujud (fasa) suatu zat tanpa menaikkan temperaturnya atau disebut juga sebagai bahan berubah fasa. 
Prinsip kerja dari penggunaan bahan berubah fasa pada bahan bangunan adalah bahan tersebut membeku (fasa padat) pada saat temperatur lingkungan rendah dan mencair (fasa cair) pada saat temperatur lingkungan tinggi. Pada saat energi termal matahari masuk ke dalam dinding bangunan tidak langsung diteruskan pada ruangan. Namun energi termal tersebut digunakan untuk mengubah wujud bahan berubah fasa dari padat menjadi cair.

Penggunaan bahan berubah fasa pada bahan bangunan memungkinkan energi termal dari lingkungan sebuah bangunan diserap oleh bahan bangunan sehingga temperatur dalam ruangan bangunan lebih stabil dan tetap rendah. Akibatnya, perubahan temperatur lingkungan luar bangunan tidak akan berpengaruh secara signifikan terhadap perubahan temperatur dalam ruangan bangunan. Rekayasa ini akan meringankan mesin pengatur temperatur ruangan (AC), sehingga energi listrik yang digunakan menjadi lebih kecil.

Terdapat penelitian yang menyebutkan bahwa penggunaan bahan berubah fasa CPO pada batako mampu menurunkan nilai konduktivitas termal dari $0,683 \mathrm{~W} / \mathrm{m}$.K menjadi $0,547 \mathrm{~W} / \mathrm{m} . \mathrm{K}$. Namun proses pembuatan menggunakan media batu apung sebagai penyimpan CPO dinilai kurang efisien ${ }^{2)}$.

Penelitian selanjutnya adalah penggunaan CPO sebagai bahan berubah fasa pada bata ringan. CPO diinjeksikan pada bata ringan dengan berbagai variasi volume ${ }^{3)}$. Pada penelitian ini menunjukkan adanya pengaruh CPO sebagai bahan perubah fasa pada bata ringan terhadap penurunan nilai konduktivitas termal. Namun pengaruh yang ditunjukkan oleh hasil pengujian belum seluruhnya sesuai dengan hipotesis awal, yakni nilai konduktivitas termalnya tidak menurun secara konstan namun juga nilainya naik pada jumlah injeksi CPO tertentu. Hal ini diduga karena kandungan CPO dalam bata ringan tidak merata yang disebabkan oleh pengisian CPO dilakukan dengan cara menginjeksi CPO ke bagian tengah spesimen dengan cara melubangi spesimen dan menutupnya dengan bahan lain (semen). Selain itu pemberian bahan lain (semen) untuk menutup lubang injeksi menyebabkan spesimen menjadi tidak homogen. Oleh karena itu, diperlukan penelitian lebih lanjut dengan mempertimbangkan tingkat sebaran CPO dalam bata ringan.

Dengan demikian, pada penelitian ini dibuat agar seluruh permukaan bata ringan dapat terendam oleh CPO. Hal ini diharapkan agar CPO yang masuk ke dalam bata ringan lebih merata dan homogen.

\section{METODE}

Penelitian ini merupakan penelitian eksperimen laboratorium dengan Posstest-Only Control Design dimana pengukuran dilakukan pada obyek kontrol yang tidak diberi perlakuan dan obyek yang diberi perlakuan. Hasil pengukuran obyek yang diberi perlakuan dibandingkan dengan obyek yang tidak diberi perlakuan.

Tahapan eksperimen dibagi menjadi tiga tahapan utama, yaitu (1) Tahap Persiapan, (2) Tahap Pelaksanaan dan (3) Tahap Analisis. Ketiga tahapan utama pelaksanaan eksperimen ditunjukkan dalam Gambar 1 berikut ini: 


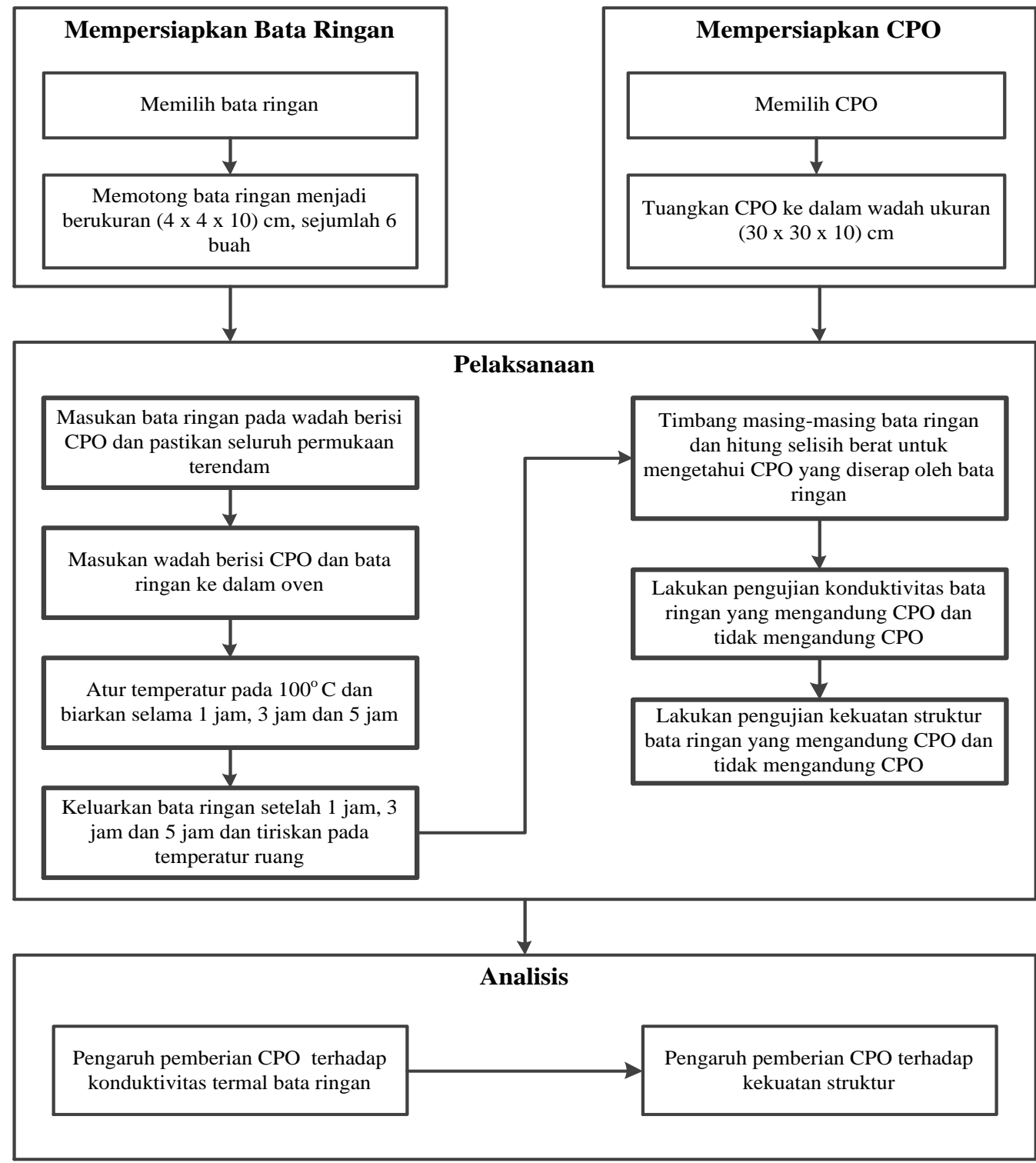

Gambar 1. Skematik pelaksanaan eksperimen

Ukuran bata ringan yang akan diberi CPO ditentukan dengan pertimbangan dimensi spesimen uji konduktivitas termal dan ukuran wadah CPO ditentukan dengan pertimbangan dimensi bata ringan yang dibuat agar seluruh permukaan bata ringan dapat terendam oleh CPO. Hal ini diharapkan agar CPO yang masuk ke dalam bata ringan lebih merata dan homogen. Temperatur CPO saat proses pembuatan bata adalah $100^{\circ} \mathrm{C}$ untuk membuat viskositas CPO lebih encer dan dapat diserap oleh bata ringan. Sedangkan variasi waktu adalah untuk memperoleh variasi tingkat penyerapan CPO sehingga bisa diuji pengaruh kandungan $\mathrm{CPO}$ terhadap konsuktivitas termal. 
Penelitian ini dilakukan pada beberapa laboratorium yaitu Workshop Desain Produk ITSB (pemotongan spesimen uji bata ringan), Laboratorium Kimia Dasar ITSB (perendaman bata ringan menggunakan CPO), Laboratorium Rock Fluid Imaging Bandung (pengujian konduktivitas termal), dan Center for Infrastructure and Build Environment (CIBE) ITB (pengujian kekuatan struktur).

\section{HASIL DAN PEMBAHASAN}

Hasil penelitian sebelumnya menunjukkan fenomena bahwa penambahan CPO dalam jumlah tertentu dapat menurunkan nilai konduktivitas termal bata. Hal ini karena CPO bersifat sebagai bahan berubah fasa, yaitu bahan yang membeku pada temperatur dingin dan mencair pada temperatur sekitar $25^{\circ} \mathrm{C}-50^{\circ} \mathrm{C}$. Mekanisme kerja CPO sebagai bahan untuk menurunkan konduktivitas termal bata ringan adalah CPO yang membeku dalam pori-pori bata ringan akan menyerap panas, sehingga panas yang diterima oleh satu sisi bata ringan tidak langsung diteruskan ke sisi/bagian lain dari bata ringan tersebut, tetapi akan mengubah fasa CPO dari beku (padat) menjadi cair. Dengan demikian, ada jeda waktu penghantaran panas yang terjadi pada bata.

Nilai konduktivitas termal bata ringan yang lebih rendah dari nilai kontrol (bata tanpa CPO) terjadi pada bata dengan injeksi CPO 2,5 ml, $5 \mathrm{ml}$, dan 7,5 ml. Pemberian injeksi CPO sebanyak $10 \mathrm{ml}$ atau lebih menunjukkan nilai konduktivitas termal lebih tinggi dari kontrol. Tabel 1 adalah nilai konduktivitas termal berdasarkan variasi pemberian injeksi CPO.

Tabel 1. Konduktivitas termal bata dengan injeksi CPO

\begin{tabular}{c|ccc}
\hline Nama Sampel & $\begin{array}{c}\text { Konduktifitas Termal } \\
(\text { Watt/m.K) }\end{array}$ & $\begin{array}{c}\text { Kekuatan Tekan } \\
\left(\mathrm{kg} / \mathrm{cm}^{2}\right)\end{array}$ & Keterangan \\
\hline ITSB I.1 & $0.12( \pm 0.01)$ & 26.25 & Injeksi 0 ml \\
ITSB II.1 & $0.06( \pm 0.01)$ & 17.50 & Injeksi $2.5 \mathrm{ml}$ \\
ITSB III.1 & $0.07( \pm 0.01)$ & 17.50 & Injeksi 5 ml \\
ITSB IV.1 & $0.08( \pm 0.01)$ & 18.75 & Injeksi $7.5 \mathrm{ml}$ \\
ITSB V.1 & $0.14( \pm 0.01)$ & 28.75 & Injeksi $10 \mathrm{ml}$ \\
ITSB VI.1 & $0.15( \pm 0.01)$ & 18.75 & Injeksi $15 \mathrm{ml}$ \\
\hline
\end{tabular}

Di sisi lain, nilai kekuatan tekan bata yang yang ditunjukkan pada Tabel 1 terlihat fluktuatif. Hal ini dimungkinkan karena bata tidak homogen.

Pada penelitian ini, bata direndam dengan CPO dengan harapan agar CPO yang masuk ke dalam bata ringan lebih merata dan homogen. Perendaman dilakukan dengan berbagai variasi waktu, yaitu satu jam, tiga jam, dan lima jam untuk memperoleh variasi tingkat penyerapan CPO terhadap bata. 
Volume CPO yang terserap oleh bata ringan setelah direndam dengan berbagai variasi waktu ditunjukkan oleh Tabel 2. Semakin lama waktu perendaman, semakin banyak CPO yang masuk pada bata ringan. Dalam waktu satu jam, CPO yang masuk terserap ke dalam bata ringan adalah 23,2 $\mathrm{ml}$. Volume ini lebih banyak dibandingkan dengan volume CPO yang diinjeksikan pada penelitian sebelumnya.

Tabel 2. Hasil pengujian konduktivitas termal

\begin{tabular}{ccccc}
\hline No. & Spesimen & $\begin{array}{c}\text { Volume CPO } \\
\text { pada Bata }(\mathrm{ml})\end{array}$ & $\begin{array}{c}\text { Konduktivitas } \\
\text { Termal }(\text { Watt/mK) }\end{array}$ & $\begin{array}{c}\text { Keterangan waktu } \\
\text { perendaman bata oleh } \\
\text { CPO }\end{array}$ \\
\hline 1. & Kontrol & 0 & $0,07( \pm 0,01)$ & 0 jam \\
2. & ITSB-I & 23,2 & $0,14( \pm 0,01)$ & 1 jam \\
3. & ITSB-III & 39,7 & $0,18( \pm 0,01)$ & 3 jam \\
4. & ITSB-V & 80,9 & $0,2( \pm 0,01)$ & 5 jam \\
\hline
\end{tabular}

Hasil pengujian menunjukkan nilai konduktivitas termal bata ringan meningkat berbanding lurus dengan peningkatan volume CPO. Hal ini sesuai dengan penelitian (Robertson, 1988) yang menyatakan nilai konduktivitas termal batuan dipengaruhi oleh komposisi batuan, porositas, dan fluida pengisi di dalam batuan. Penelitian menyebutkan bahwa nilai konduktivitas termal batuan yang berisi fluida cair umumnya lebih tinggi dibandingkan dengan nilai konduktivitas termal yang berisi fluida gas/udara.

Kekuatan bata ringan yang diberikan CPO ditunjukkan pada Tabel 3.

Tabel 3. Hasil uji tekan bata dengan perendaman

\begin{tabular}{cccc}
\hline No. & Spesimen & Kekuatan Tekan $\left(\mathrm{kg} / \mathrm{cm}^{2}\right)$ & $\begin{array}{c}\text { Keterangan waktu } \\
\text { perendaman bata oleh CPO }\end{array}$ \\
\hline 1. & Kontrol & 32,89 & 0 jam \\
2. & ITSB-I & 27,91 & 1 jam \\
3. & ITSB-III & 22,46 & 3 jam \\
4. & ITSB-V & 29,22 & 5 jam \\
\hline
\end{tabular}

Hasil uji tekan menunjukan penambahan CPO pada bata ringan tidak memberikan korelasi yang linear terhadap kekuatan tekannya.

\section{KESIMPULAN}

Kesimpulan dari penelitian ini adalah sebagai berikut:

1. Jumlah volume CPO yang diinjeksikan pada bata lebih berpengaruh dibanding pemerataan CPO pada bata.

2. Penambahan $\mathrm{CPO}$ yang efektif untuk menurunkan konduktivitas termal bata ringan adalah $2,5 \mathrm{sd} 7,5 \mathrm{ml}$ per $160 \mathrm{~cm}^{3}$.

3. Tidak ada korelasi linier antara volume CPO yang ditambakan dengan nilai uji tekan.

4. Diperlukan kajian lebih lanjut dalam perendaman bata ringan dalam CPO dengan volume tertentu. 


\section{UCAPAN TERIMA KASIH}

Ucapan terimakasih kami sampaikan kepada Yayasan Institut Teknologi Sains Bandung atas dukungan dana yang diberikan. Ucapan terimakasih juga kami sampaikan kepada LPPM ITSB, dosen dan mahasiswa pada Program Studi Teknologi Pengolahan Sawit, serta semua pihak yang membantu terlaksananya penelitian ini.

\section{DAFTAR PUSTAKA}

1) Krischenbauer. (1960). Fat and Oil.An Outline of Their Chemistry and Technology. New York: Reinhold Publishing Co.

2) Laila, L. (2013). Penggunaan Bahan Berubah Fasa pada Dinding Bangunan dalam Sistem Pengkondisian Udara Pasif, Tesis, Teknik Mesin FTMD ITB, Bandung.

3) Laila, L., Darma, A. Y., (2020). The Application of Crude Palm Oil (CPO) within Lightweight Concrete in Passive Air Conditioning System, Journal of Physics: Conference Series, 1456012034. 